\title{
Development Dynamics at the Margin
}

Professor Hiranya K Nath ${ }^{\dagger}$

The development paradigm in the last quarter of a century has largely been one of economic growth, increased global interactions among people, and aspirations (revealed or/and hidden) for political freedom and human rights. The advances and proliferation of information and communications technology (ICT) have removed many barriers and have redefined the nature of economic, political and social interactions. These developments have also created new haves and have-nots in the society. This division is more pronounced in developing countries like India where more than one-third of the population is still illiterate. In this new order, information is the source of economic, political and social power. The technology and its proliferation have created opportunities for a large number of people, even for those who would not stand a chance in the world that we used to know. However, the existing institutional framework needs a major overhaul for these changes to be beneficial to everyone in the society. Unfortunately, as we all know from history, such changes in institutions do not take place overnight.

In this new world, certain changes have swept across societies (and groups within the societies) and "convergence" seems to have been the buzzword. For casual observers, these trends may signify an inevitable death of the struggles of groups and people who are living at the margins of cultural, political and even economic identities. However, an attempt at understanding the fundamentals of these global changes would reveal a completely different picture - full of opportunities for these people. In this information age, the possibility of reducing information asymmetry and enhancing transparency is enormous and

\footnotetext{
${ }^{\dagger}$ Professor of Economics, Department of Economics and International Business, Sam Houston State University, Huntsville, Texas 77341-2118 (USA). E-mail: eco_hkn@shsu.edu
}

has created a chance for innate human goodness and compassion to bring hopes to those who live on the fringes of societies and have been struggling through the ages. On one hand, there are greater opportunities for marginal people to narrate their stories and articulate their aspirations in front of a larger audience. On the other hand, there have been greater initiatives by the people at the core (mainstream) to change the conditions of those at the margin for better.

The current issue of Space and Culture, India includes two reviews, two special articles and three research articles by authors from different disciplines. The issues and initiatives of the people living at the margin of societies are the main talking points of these essays. While some articles focus on understanding the issues, others delve deep into the struggles and initiatives surrounding these people.

In his review article "Making the Public Distribution System Work", Debarshi Das argues that PDS becomes more effective and successful in providing essential food items at government-determined low prices to the economically marginal group when it has universal coverage. The inclusion of everyone under its coverage limits the scope of corruption. This strategy may be very important when there is food inflation as the fair price shops have the incentive to divert PDS food supplies in order to make higher profit during such time. He also argues that restructuring the delivery mechanism and greater monitoring are important for PDS to be successful.

In the review of "The Prohibition of Employment as Manual Scavengers and Their Rehabilitation Act, 2013", Aparajita Baruah discusses India's constitutional obligations towards a marginal group - the Dalits (untouchables) who have traditionally been involved in manual scavenging. She also discusses the evolution of various measures that have led to the enactment of the law that seeks to completely eliminate manual 
scavenging and rehabilitate the Dalits in the mainstream of the society.

In a country as large and diverse as India with divergent histories, the relatively young nationstate has been often ruthless and brutal towards the people living on the fringes (both geographically and historically) in the name of nation-building. The use of the Armed Forces Special Powers Act (AFSPA) in Manipur and other states of Northeast India is an example. Emboldened by this act, the Indian army personnel have been involved in gross violations of human rights by engaging in rapes, kidnappings, killings and fake encounters with no legal recourse for the victims. The political representation of these states in the parliamentary democracy is weak and inconsequential. Aparajita Sharma, in her special article, highlights the protest of Irom Chanu Sharmila against such violations. The hope and determination that her protest inspires are contrasted with the insurgency that manifests the rage of the young Manipuris against such atrocities.

The Tibetan refugees in Nepal and India are keeping their hopes of a free Tibet alive in the midst of the adversities they are facing in their host countries. In particular, the hostility of the Nepalese administration in the wake of a new geo-political realignment with the emerging superpower - China has created an environment of enhanced uncertainty for this marginal group of people. In their article, Venkat Pulla and Kanchan Prasad Kharel highlight the close association between the principles of karma as the guiding philosophy of life and the weaving of carpets as the main economic vocation among these refugees. This blending of spirituality with an earthly endeavour gives them the resilience and hope to move forward.

Esita Sur delves deep into the question of identity of Muslim women as a marginal group in the Indian society. The marginal identity of this group is not only confined to their socioeconomic status but is also extended to the semantic representation in words like veiled, passive, meek victim, often used in political and academic discourses over Muslim women in India. The politics of constructing the "other" identity for this group ultimately leads to its alienation and deprivation, which have their impact on their socio-economic status.

The wind of "development" has also influenced the marginal hill areas of Uttarakhand where people's life and livelihood are intricately related to the eco-system that includes land, water and forest. As deforestation leads to environmental degradation, and migration of the menfolk in search of better economic opportunities in urban areas leads to demographic realignments of the society, the economic responsibility of women has become more prominent. In her research article, Suman Singh discusses how women's understanding of the importance of human-nature interactions for survival and their efforts to maintain the traditional agro-ecosystem have brought hope for environmental sustainability.

The rapid economic growth that India has experienced in last two decades has also brought rapid urbanization. The basic amenities of urban life are under tremendous pressure with this overgrowth of towns and cities. In their article, "Drinking Water in Guwahati City: Its Past, Present Status and Associated Problems", Prasanta Bhattacharya and Rajashree Borah discuss the challenges of drinking water in Guwahati, the largest city and the gateway to Northeast India. Their study shows that the problem of drinking water shortage is more acute in the peripheral areas (at the margin of urban-life) of the city. The article highlights the need for revamping the water supply system in Guwahati. 